\title{
Moving the Goalpost: “Come-We-Stay” Practice in Menchum Division (MD), Cameroon
}

\author{
John Mih Uka
}

\begin{abstract}
This paper seeks to understand people's perception of "come-we-stay" (CWS) cohabitation in Menchum Division (MD), Cameroon. As in most of Africa, marriage is a valued institution that ensures the continuation of the family tree. The emergence of CWS is gathering momentum fast in many communities in the country much to the dislike of the church and custodians of tradition who perceive CWS to be a cheap union form that breaches marriage norms. This paper seeks to address whether the emergence of CWS has affected marriage perceptions in MD. Initially, quantitative data were collected via online survey disseminated via Facebook. The time-efficiency, economic viability, convenience and anonymity of this method made it a viable method for this study. Later, however, due to a low response to the Facebook link, the online survey was constructed into a questionnaire and administered to the same target population. Questionnaires were relevant to this study because they could be self-administered. However, the questionnaires were limited as they did not allow for attention to details. The data were analysed using content analysis.
\end{abstract}

\section{Keywords}

Come-we-stay (CWS), cohabitation, union, marriage, Menchum, Cameroon

Come-we-stay (CWS) has a longstanding history in many communities. Its ramifications depend on the context and polemics used (Browning 2013; Moore and Govender 2013; Gilbertson 2014; Wong 2015). In most countries, it is not an end itself. For instance, in the United Kingdom, cohabitation is akin to CWS and is given considerable recognition if it subsists two years or children are involved (Wong 2015). These dynamics are redefining social norms in some communities ${ }^{1}$ in Cameroon, yet there is a dearth in studies on the concept. A rigorous literature search would indicate that there have been no previous studies on CWS in Menchum Division (MD). To prepare the readers' mind, it is important to briefly highlight the sociological context of MD.

\section{RESEARCH CONTEXT}

MD shares boundaries with Manyu and Momo divisions on the southwest, Mezam and Boyo in the southeast and Donga Mantung to the northeast and the Federal Republic of Nigeria on the northwest (Kaberry 1952). MD comprises four sub-divisions, Wum Central, Menchum Valley, Fungom, and Fru-Awa and it has a rich diversity of people like the Aghem, Esu, Bafmeng, Weh and Kung amongst

aUniversity of Lincoln, UK

Correspondent Author:

John Mih Uka, Social and Political Sciences, University of Lincoln, LN6 7TS, UK

E-mail:mihukason@yahoo.com 
others who exhibit similar yet distinct cultural practices because of their migration histories (Vubo 2005). This cultural pluralism is underpinned by traditional and patriarchal relationships. Nonetheless, women are dominant in subsistence farming (Kah 2013) and therefore act as shock absorbers, ensuring food security thus feeding the burgeoning urban population. However, the majority of these women remain poor because cultural practices limit their access to resources and collateral securities (Endeley 2001; Fonjong 2001; Alasah 2008; Agheneza 2009).

Social life in MD is epitomised by matrilineal and patrilineal succession, high frequency of polygamy, the levirate and trade. The levirate is a practice where the widow is married to the brother of the deceased husband (Kouyate 2009). The principle of primogeniture $^{2}$ is applied where the first child is a son but often disputed where the first child is a female and there is no will. Marriage is considered as an invaluable institution and is solemnised by the payment of bride price which unites the two families (Amin and Bajracharya 2011). Children are seen as a source of status and wealth (Calves 2010). Polygyny is common making it possible for wealthy men to marry many wives. This is reinforced by Justice Nganjie's definition of marriage in Cameroon as "the union between one man and one or more women to the exclusion of other men" (Bobga 1999: 55). Marriage entails the fulfilment of marriage rites preceded that cohabitation and procreation (Weinger 2009). But CWS's emergence is creating social tensions which are redefining marriage social order.

\section{LITERATURE REVIEW}

Research on MD has predominantly centred on farmer-grazier conflicts (Ngwoh 2006; Fonchingong Vubo, and Besseng 2008; Manu et al. 2014), social care (Lang 2012), and chieftaincy succession (Tem 2013) amongst others. Despite the importance of marriage, there is a paucity of literature focusing on this topic and seemingly none on CWS. The dearth in CWS studies in Africa despite its prevalence means that the practice can no longer be overlooked. According to Blum (2006), cited in Chilisa et al. (2013), premarital intercourse is commonplace in sub-Saharan Africa with $60 \%$ of women having sex before their 18th birthday and 33\% of young women giving birth before their 20th birthday (Chilisa et al. 2013). Pre-marital sex has become such commonplace that even religious young people do not consider it sinful (Meekers and Ahmed 2000). The paucity of studies on the impact of premarital childbearing on the transition to marriage (Calves 2010) makes the exploration of CWS perceptions imperative because of the nexus between premarital childbearing and marriage.

The postponement of first marriage in sub-Saharan Africa has led to an increase in the prevalence of pregnancies and births among formally unmarried adolescents (Gage and Meekers 1994). Although marriage remains a priority among young Cameroonians (Johnson-Hanks 2007; Calves 2010), there has been a change in marriage and family formation patterns in Africa (Moore and Govender 2013). Marriage rates are generally plummeting among women while cohabitation is increasing (Hosegood, McGrath, and Moutltrie 2009). According to Hosegood et al. (2009), one of the main reasons for the changes in the rate and patterns of marriage in South African is cohabitation, undertaken as "part of the process of postponing marriage or as an alternative to coupling or both” (Moore and Govender 2013: 624). Even though most agreed cohabitation as a precursor to getting married materialises making CWS a valuable mechanism for resolving issues or sharing resources through planning together and joint space sharing, there are potentials for danger when this backfires (Moore and Govender 2013). This shows that cohabitation is only a means to an end and not an end in itself. However, the limited evidence of CWS materialising into marriage in other countries like Cameroon where its practice is the knitted effort of intersectional variables makes understanding the 
concept imperative.

According to Njiru (2008), CWS is a "fact arrangement not sanctioned by civil, religious or traditional authority but where a man and woman decide to live together as husband and wife" (Njiru 2008: 4). Put differently, CWS is like a marriage arrangement between two consenting parties who have no obligation to declare their cohabitation to their families (Come-We-Stay ${ }^{3}$ [CWS] 2013). Building on these definitions, CWS therefore denotes a form of cohabitation or conjugal relationship between two consenting heterosexual adults who live together and procreate when marriage rites have not been formalised. In other words, CWS is a euphemism describing conjugal relationships between two partners who cohabit and procreate without fulfilling marriage rites at civil, customary nor religious level. Such unions do not receive parental consent or blessing (CWS 2013) but childbirth may trigger formalisation by way of a follow-up with marriage rites.

Unlike marriage arrangements in Africa which entail a long course of interfamily negotiations and exchange (Fredericksen 2000; Sijpt 2012), CWS is born out of the will to informally cohabit as a couple. Gilbertson (2014) argues that the expenses involve in formalising marriage make those who cannot afford to pay for a full wedding to resort to CWS. To give their union the face of marriage, the man invites the woman and they start living and sleeping together followed by "informal marriage" (Gilbertson 2014). The name is therefore derived from the manner in which the relationship is contracted. Such unions are prone to sudden dissolutions because of limited commitment resulting from none gift exchange and bride price (Gilbertson 2014). Gilbertson's argument that the laxity within CWS relationships results from bride price non-payment is not wholly true because research suggest there is often commitment from the women seeking to secure permanent relationships (CWS 2013). Distinguishing CWS from cohabitations that precede the socially constructed "knock door" in MD is imperative. Knock door is a culturally coined concept for the traditional engagement where the groom's family introduces itself to the would-be bride's family and declare their intention to marry the would-be bride. Knock door denotes the partners' engagement or the commencement of bride price proceedings and sometimes triggers co-residence (Calves 2010). Unlike CWS, such co-residence receives family blessing, but the man is still deemed to have formally "borrowed the wife" pending bride price payment. CWS therefore differs from marriage in the sense that while marriage is sanctioned by bride price payment proceeded by "formal handing over of the wife to the husband's family", these components are absent in CWS. Bride price payment accords social respect to couples in marriage, but those in CWS do not get this respect and become objects of ridicule within traditional settings in their communities because they have not fulfilled marriage rites at any of three levels. Moreover, while marriage couples enjoy social acceptance and respect from extended family given the level of kingship (Verhoef 2005), those from CWS may not especially in cases of desertion.

CWS is prevalent among the youths (Njiru 2008; CWS 2013) and to some extent among people aged above 20 (Moore and Govender 2013). It starts when the parties begin living together and ends when marriage rites are formalised. Influenced by the operation context, CWS create responsibilities akin to marriage like common gender division of labour in the household and sexual exclusivity (Njiru 2008). Empirical observation suggests that CWS is both planned and unplanned. It is planned when the cohabitation is initiated for independence or convenience and unplanned when the cohabitation is triggered by unpleasant events like pregnancy leading to the rejection of the woman by her family. Family history, social class, and religion influenced the decision to reject the pregnant teenager. Finance and accommodation are the determining factors of who host the union. 


\section{DATA COLLECTION AND METHODS}

Sample survey was the principal research method because of MD's cultural pluralism. It was operationalised by questionnaires. Besides the easy and economic viability of questionnaires (Bowling 2014), they provided greater control to respondents in the sense that they were completed at respondents' convenience and thus gave them the opportunity to attempt most questions (Sarantakos 2005). Moreover, the self-administered questionnaires were time-efficient allowing for anonymity which has potentially for encouraging honesty particularly in exploring sensitive areas (Robson 2011). In addition, they were flexibly designed allowing spaces for additional information (Robson 2011). The inclusion criterion was being of MD origin and has actually lived in MD or not being of MD origin but have lived in MD for at least three years prior to the study. Participation was voluntary and confidentiality and anonymity were maintained throughout the study by non-request of personal data. Data were collected by means of self-completed questionnaires comprising seven items initially via online survey (SurveyMonkey) designed and posted on Facebook with the link for participants to complete. To increase participation, the survey was also disseminated via email to the same sample without Facebook accounts.

Due to the low response rate, the survey questions were composed into a word document and distributed to the same target population for self-administration, mindful of sample duplication. Despite the merits of the questionnaires listed above, they were limited in the sense that they were self-administered and therefore gave no room for probes (Robson 2011) and also excluded those who could not read and write but who may have valuable contributions to make. The implication is that the findings could only be described without making further meaning from them. Secondly, MD's demographic profile means that respondents from Wum, Esu, and Weh have been overrepresented the survey, but effort was made to represent most villages in the sample. Thirdly, the exclusion of Fru Awa Sub division for logistical reasons starved the study of some valuable contributions. Data were collected between August 2014 and March 2015 and analysed using content analysis.

\section{PRESENTATION OF FINDINGS}

A total of 106 questionnaires were collected, 31 via SurveyMonkey and 75 through administering questionnaires. $62.26 \%$ of the 106 respondents said CWS was very common, $34.91 \%$ said it was common, $4.72 \%$ said it was uncommon, and $2.83 \%$ did not respond. An overarching 83\% attributed CWS's prevalence to social and economic factors compared with $11.3 \%$ who attributed it to a combination of political, economic, social, religious, and cultural factors. Five point seven percent (5.7\%) did not answer, $45.28 \%$ said the youths benefit more because they can cohabit and procreate without observing marriage procedure and even partake in some traditional rites if children are involved compared with $24.53 \%$ who said both the youths and the adults benefit more especially in poor homes where matured girls are perceived as sojourner by their families and as such pressurised to marry, $4.72 \%$ said the community benefits more because CWS curbs sexual promiscuity by encouraging stable relationships, takes away the burden of having to provide for mature unmarried females from their families and above all encourages the development of mutual understanding between people who envisage spending their lives together. These views underscore the pivotal role of poverty in perpetuating CWS albeit in reality CWS's prevalence is a product of intersectional variables. $62.26 \%$ had general knowledge of CWS compared with $36.8 \%$ who were either practising or had practised CWS prior to the study, .94\% did not answer. Colaizzi (1978) framework was used to handpick 
significant statements and phrases pertaining to CWS.

\section{ANALYSIS AND DISCUSSION OF FINDINGS}

These findings heighten the importance of finance in marriage. Getting married in MD is demanding and comes with huge responsibilities. Marriage is an agreement between two lineages not a contract between two individuals and validated by bride price payment (Anderson 2007; Bishai and Grossbard 2008; Hague and Thiara 2009; Amin and Bajracharya 2011; Rautenbach and du Plessis 2012) which besides granting husbands' rights over the children resulting from the union, represents an expression of appreciation for the bride's upbringing (Guyer 1984; Calves 2010). Bride price payment creates social bonds between the bride and the groom's families which entails additional responsibilities on the groom because he is expected to make mandatory contributions when the bride's family have important celebrations like death celebrations or bereavement. Thus, the costs of solemnising marriage and the accruing responsibilities partly precipitate CWS. Consequently, marriage is redefined in parts of Cameroon like East Cameroon where high bride price has made marriages flexible (Sijpt 2012). The form, direction, and amount of money paid as bride price vary across villages but on average, less preliminary arrangements, it cost between 40 and 50 thousand CFA (40,000 CFA and 50,000 CFA) in cash money and a goat to give as bride price to the bride's male parents and at least five 20 litres (tins) of palm oil to the bride's mothers as bride price. This can be daunting for the average male and explains the special financial commitment from men prior to bride price payment. These events, often coordinated by the groom's family head or representative, are costly as the would-be groom spices the celebration with drinks (Calves 1996). On bride price payment day, the groom and his family come in procession, bearing gifts for the bride's family which are evaluated according to custom and tradition. The bride and the groom's presence during the occasion are dispensable because marriage under native law and custom is fundamentally by proxy (Ngwafor 1996). Although the couple can choose the type of marriage they want, this often comes after the traditional marriage which further underscores CWS's prevalence.

As depicted in Table 1, two major camps emerged from the findings: those who favoured CWS and those who were against it. Those who favoured CWS argued that CWS is a convenient union because it evades the rhetoric of marriage. Elucidating this, one respondent said "CWS has simplified the process of traditional marriage where individuals had to wait until they went through a certain process before they could share the same roof". Thus, the fact that love, understanding and the sharing of responsibilities in personal space overrides due process of marriage makes CWS a convenient relationship. Stretching this further, respondents said: "I think most get into CWS because they might not be ready financially to marry appropriately. Those who get into CWS eventually get marry", "Life is about happiness and if both parties involve are happy in it, it is worth it", and "CWS is the beginning of marriage". The free entry and free exit characterising CWS was also linked to minimising cost of living particularly for those out of their villages of origin. The tasking town life falls squarely on those with low educational levels and makes it difficult for them to secure a job (Fonchingong and Ngwa 2006). When they do, the wages are incommensurate to living cost, making cohabitation, especially for those in existing relationships, a cheaper and more realistic option. Conjectured this way, CWS becomes a creative response to social norms toward marriage. Elucidating CWS's pragmatics, one respondent remarked: "I personally find nothing wrong with CWS given the fact that the move is another means used by individuals to assist each other in many different ways, CWS has simplified marriage". CWS is therefore 
Table 1. Data and Key Themes Deduced From the Data

\begin{tabular}{|c|c|c|c|c|}
\hline \multicolumn{5}{|c|}{ How prevalent is CWS in MD? } \\
\hline Very common & Common & Not common & Don’t know & $\begin{array}{l}\text { Number who did not } \\
\text { answer }\end{array}$ \\
\hline $61(62.26 \%)$ & $37(34.91 \%)$ & $5(4.72 \%)$ & $3(2.83 \%)$ & \\
\hline \multicolumn{5}{|c|}{ Which set of factors contribute more to CWS prevalence in Menchum? } \\
\hline Social and economic & Political and social & Economic and political & All of the above & \begin{tabular}{|l} 
Number who did not \\
answer
\end{tabular} \\
\hline $88(83 \%)$ & 0 & 0 & $12(11.3 \%)$ & $6(5.7 \%)$ \\
\hline \multicolumn{5}{|c|}{ Who benefits more from CWS in MD? } \\
\hline Youths & Youths and adults & Community & \begin{tabular}{|l|} 
All of the above in \\
varying degrees
\end{tabular} & \begin{tabular}{|l}
$\begin{array}{l}\text { Number who did not } \\
\text { answer }\end{array}$ \\
\end{tabular} \\
\hline $48(45.28 \%)$ & $26(24.53 \%)$ & $5(4.72 \%)$ & $24(22.64 \%)$ & $3(2.83 \%)$ \\
\hline \multicolumn{5}{|c|}{ Source of CWS experience? } \\
\hline General knowledge & & Had lived or living in it & & $\begin{array}{l}\begin{array}{l}\text { Number who did not } \\
\text { answer }\end{array} \\
\end{array}$ \\
\hline $66(62.26 \%)$ & & $30(28.3 \%)$ & & $1(.94 \%)$ \\
\hline \multicolumn{5}{|c|}{ In your opinion, do you think CWS has any effect on marriage perceptions? } \\
\hline Yes & No & Don't know & & $\begin{array}{l}\begin{array}{l}\text { Number who did not } \\
\text { answer }\end{array} \\
\end{array}$ \\
\hline $73(68.87 \%)$ & $20(18.87 \%)$ & $3(2.83 \%)$ & & $10(9.43 \%)$ \\
\hline Advantages of CWS & & & Disadvantages of CWS & \\
\hline \begin{tabular}{|l|} 
Convenience \\
$15(15.9 \%)$ \\
\end{tabular} & & & $\begin{array}{|lrr|}\begin{array}{l}\text { Fertility } \\
(22.26 \%)\end{array} & \text { testing } & 21 \\
\end{array}$ & \\
\hline $\begin{array}{l}\text { Rapport building } \\
13(13.78 \%)\end{array}$ & & & \begin{tabular}{|l|} 
Violation of marriage \\
culture \\
$65(68.9 \%)$
\end{tabular} & \\
\hline $\begin{array}{l}\text { Sense of belonging } \\
5(4.72 \%)\end{array}$ & & & \begin{tabular}{|l|} 
Sense of insecurity \\
$65(68.9 \%)$
\end{tabular} & \\
\hline
\end{tabular}

fulfilling for those with no marrying or remarrying intentions (Tabutin and Shoumaker 2004: 469-470) and assuages the social stigma associated with female headed households by providing the much needed male role model. By filling this gap, CWS overcomes cultural differences relating to parenting (Bornstein 2002).

Secondly, CWS encourages rapport building among the consenting parties in a "coupled life" with the intention that this would inform their decision to progress the union to marriage (Njiru 2008). Since compatibility is a crucial element within relationships (Gray 1996), CWS provides an assessment platform for spousal suitability by enabling the building of mutual understanding. Gauged this way, CWS is plausible to observe compatibility and also lay siege to divorce. In assessing each other, the partners postpone the entering into formal marriage but not cohabitation or union formation (Johnson-Hanks 2007). This is buttressed by the excerpt from Johnson-Hanks (2007: 651) study on dating among the Betis in Yaoundé, Cameroon:

We tell ourselves, this might lead to marriage... but we have to first stay together a long time to know his true comportment, to see what he doesn't like in order to avoid problems. Because when you realise that he has some faults, you can say no. You can leave. If you don't have children, you are free... but sometimes you can do five years and you do not see too many black spots, so you say "good". If he proposes marriage, you accept. 
Thirdly, CWS gives the partners sense of belonging. Consistent with the fact that identity formation is crucial among the youths (Erikson 1982); CWS offers the cohabiting partners a sense of identity. Showcasing this, one respondent argued that although CWS is a "consolation price for marriage", it was a plausible union because it allows the partners to live a "coupled life" and function like other members within the community. Accordingly, respondents advocated CWS for people who "love each other but lack the social and economic requirements to formalise their relationship”. Put differently, although CWS provides what Gofman (1963), cited in Blaine (2007: 175) called "spoiled identity" defined as "being discredited in the eyes of others" (Blaine 2007: 175), nonetheless, CWS is an alternative marriage for those unable to afford marriage cost.

By contrast, CWS critics enabled the following themes to be deduced: Twenty-two point twenty-six percent (22.26\%) of respondents said CWS was a fertility testing for women. Childbearing among unmarried Africans is often a plausible step in the marital process (Meekers 1995) and women are expected to prove their fertility before their partners agree to marry them (Oppong and Wery 1994). As in most parts of North Westregion of Cameroon where marriage and motherhood are revered (Verhoef 2005) and divorce frowned at, ensuring spousal fertility is crucial. CWS therefore provides a "waiting game" avenue for women to prove their fertility through pre-marital pregnancy because people are sceptical of getting married and unable to have children. This conception makes the global plummeting fertility in most parts of the world (Wattenberg 2004; Lutz, Skirbekk, and Testa 2006) insignificant because fecundity continues to determine women's status (Larsen 1995; Seth 2001; Weinger 2009). Fecundity is therefore a "relationship stabiliser" and a platform for permanence (CWS 2013) with children used as bargaining weapons for permanence because they give men and women the social licence to fulfil certain tradition rites (Calves 2010), like the annual dance of dua, funki and jitesem of the Aghem, Esu and Weh respectively. The joy of motherhood which represents "the purpose of life and the happiness of the woman" (Callister et al. 2010), therefore supersedes other relationship benefits. This is reinforced by Weinger (2009: 47) in her study of infertile Cameroon women when she highlights that bride price payment is actually construed to "purchase the woman's womb". The desire to have children therefore nullifies any birth control measures (Rwenge 2000). In some cases, the union is formalised shortly after birth of the baby because the paramount goal of marriage has been satisfied.

However, passing the fertility test does not guarantee that the union would metamorphose into marriage. This consequently impacts on women's marriage chances. If having children out of wedlock reduces women's chances of getting married (Calves 1996); this is even higher when women have them in CWS. Research shows that women who have children out of wedlock are .63 times likely to marry compared with other women without (Calves 2010). Moreover, the fact that a woman bores a child for another person makes her "less attractive as a spouse to a man who is not the biological father of her child" (Calves 2010: 298). Such women are derogatorily described as "second-hand". Women are caught at the crossroads of having children to procure permanent relationships, even though this potentially diminishes their marriage chances. This underscores patriarchy at work! Cameroon writers use satire and melodrama to highlight patriarchy's impact on women. Illustrating this in his fictional work Isn't Woman Woman's Worst Enemy? An Appraisal of Liking and Beyala, Dingome (2013: 232) argued that patriarchy "defines and controls women through anonymous labelling, exploiting their marketability, apportioning total blame to them in childless relationships, smothering their talents through forced prostitution and rape, exercising double standards in punishing unfaithfulness and 
favouring male lineage through son preference”. This puts pressure on women to identify with other women and act within a cultural decorum.

Secondly, 68.9\% of respondents said that CWS was a misgiving destroying MD's cultural heritage. Culture denotes an embodiment of beliefs, language, social norms and values that enable the creation of a sense of solidarity and belongings among those with shared interest (Zeh et al. 2014). Culture therefore gives a people a sense of belonging. Viewed this way, CWS is an antithesis of a culture where marriage formalisation precedes cohabitation. Illustrating this, one respondent remarked "It is difficult to perform marriage rites when both of you are already living together... it has negative effect because the values and pride of normal marriage rites are absent; so strangers think most ladies are desperate for men or cannot make it without men”. Generally, marriage in Cameroon signifies cooperation between the families (Sijpt 2012) in the sense that it creates social interdependence (Wong 2015) which is weak in CWS. Marriage therefore enlarges and strengthens family ties and brings responsibilities; son-in-laws are obliged under custom and tradition to support their in-laws during events and vice versa. By contrast, men practising CWS, shirk such responsibilities with the knowledge that they are incoercible. The shirking of responsibilities partly makes CWS socially unacceptable. Some respondents argued that CWS tarnishes the image of the couples' families as it indicates to the community that the family is irresponsible to raise responsible children or desperate financially to allow the children in CWS.

Thus, in violating marriage culture, CWS deprioritises marriage by making the social respect and identity women secure upon marriage (Yana 1995; Calves 2010) dispensable. CWS moves traditional marriage to the brink of collapsing by impacting on the longstanding tradition of getting married first before enjoying the accrued benefits. According to respondents, CWS is inconsistent with Christianity and Islam and an "easy channel promiscuity has taken to multiply unchecked and caused parents to lose parental control and authority vis-à-vis the life and future of the children". Although pre-marital intercourse is common among young Cameroonians especially in urban areas (Calves 1996; Sijpt 2012), CWS escalates and "normalises" it. Portraying the effects of dating on marriage among the Betis in Yaoundé, Johnson-Hanks (2007: 642) argued that "Marriage rates have fallen, the rituals marking the transition to marriage have been altered and reordered, and women's expectations of marriage have changed... marriage has gone from a prerequisite for female adulthood to a sign of pecuniary honour”.

Thirdly, CWS incubates a sense of insecurity as men "no longer take the women serious especially if children are involved" because the evasion of marriage formalities takes away the precondition of formal marriage before cohabitation. Though CWS exonerates women from the extended effects of bride price like the levirate (Uka 2004), their positions are generally insecure because CWS is ambivalent and experimental in terms of duration and progress to marriage. Researching simple relationships in East Cameroon, Sijpt (2012: S84) found that such relationships were insecure because of the absence of "clear future visions or commitments". Thus, CWS's temporariness increases women's vulnerability to intimate partner violence because regularising such relationships depends on the women's fecundity and subservience to their partners. One respondent remarked: "Women in CWS live in constant fear of being kicked out at any time when what binds them (love) shifts to another woman's favour". This is exacerbated by the fact that some women enter CWS as a precondition for permanence and when these women asked their partners to fulfil pre-agreed promises, men perceive them as vulnerable or desperate and take advantage of them physically, emotionally, and financially. This uncertainty makes such women to live in perpetual fear of the 
relationship ending abruptly or being expel from the home. The problem of having to face the family who disapproved of the cohabitation and becoming homeless makes some women, particularly from less privileged backgrounds, to endure abuse. The absence of social housing in Cameroon exacerbates this vulnerability and provides a context for gendered power imbalance because social norms make CWS a secondary relationship.

Using CWS's temporariness as an opportunity to test women's fertility is consistent with studies in Kenya where having children was a condition for permanence (CWS 2013). Similarly, using children as "passports" to marriage or permanence is consistent with Anitha's study (2011) on South Asian women with insecure immigration status. In this study, Anitha revealed that women joining their husbands as wives or fiancées before the Domestic Violence Rule 2002 in the UK endured domestic violence to have a settled immigration status for fear of being deported if their marriages broke down within the two year probationary period of residency because of the no recourse to public funds clause. Women in such relationships were in a double bind. They could not leave because of susceptibility to "abuse from their families on return for leaving marriage" and their continued stay in the UK was made precarious by their non-access to public funds (Anitha 2011: 1264).

The convenience of CWS in MD is consistent with studies elsewhere in Africa (Frederiksen 2000; Browning 2013; CWS 2013). Browning argues that though CWS is flexible and convenient in Tanzania, the partners "do not trust each other" and stay in it with the hope of "going anytime they feel as to" (Browning 2013: 154). Similarly, Fredericksen argued that the reasons young Kenyans enter into CWS are the same as those of young Americans or Danes. Young Danes or Americans enter into CWS for "a combination of love, sympathy and convenience" (Frederiksen 2000: 216). However, Fredericksen cautions that although most CWS partners engage in it for financial benefits or convenience, CWS pragmatics are more complicated to those in it than from the perspectives of those on armchair theorising. From the foregoing, even when the partners genuinely intend CWS, the fact that the man has the upper hand to regularise the union increases the woman's vulnerability to abuse.

Maslow's five-level hierarchy of basic needs provided a tool to analyse CWS' convenience. According to Maslow (1998), cited in Medcalf, Hoffman, and Boatwright (2013) human beings have potentials and strive progressively to reach their full competence (Medcalf et al. 2013). Maslow argued that meeting the needs of one level progresses the individual to an upper level. Put into perspective, meeting physiological needs like oxygen, food, and water which sustain life activates safety needs. Accordingly, until the physiological and safety needs are met, aspiration for a higher level is unattainable. Maslow believed that loneliness and alienation are surmounted by giving and receiving love and affection, thus gaining a sense of belonging. Thus, satisfying the first three levels precedes the reciprocal needs for self-esteem and respect from and toward others which when realistically stabilised, gives the individual self-confident and value; failure of which potentially makes the individual to fell "inferior or worthless" (Medcalf et al. 2013: 1325). Maslow attributed the non-attainment of self-actualisation to societal barriers (Medcalf et al. 2013). Contextualising this, CWS becomes a creative response to societal barriers to marriage because it meets the needs of youths who need partners cannot afford marriage. For practice therefore, formal and informal services are required to support and empower young people toward regularising their unions. Partnership agreements like the Divisional Delegation for Women's Empowerment and the Protection of the Family-councils' agreement facilitating union regularisation ${ }^{4}$ should be encouraged. 


\section{CONCLUSIONS}

This paper aimed at examining CWS perceptions in MD and the findings show that CWS is making seismic cultural shifts in marriage perceptions. Put simply, CWS is moving the goalpost of marriage because it is displacing formal marriages. The majority of respondents in the sample had general CWS knowledge; nonetheless, based on the data, it can be inferred that CWS is not freely condoned in MD. CWS is heavily criticised in MD but it is important to appreciate it within its specific context, because it is a union on its own right seeking recognition. Elsewhere in Africa, Kenya for example, the Marriage Bill (2012) is designed to convert CWS cohabitations subsisting after six months into legal marriages (BBC News 2014). In the UK, such unions are given formal recognition without the pressure of progressing them to permanence. Reflecting on the views of respondents who had or were currently practising CWS, it is plausible to say that the motivations for CWS are more complicated that only those actually into it can better appreciate. Further studies are therefore required on CWS dynamics and transitions into marriage.

\section{Notes}

1. BBC African News, November 9, 2012. Available at http://www.bbc.co.uk/news/world-africa-27206590.

2. The practice where all property goes to the first son.

3. CWS, 2013.

4. Personal communication with the divisional delegate for Women's Empowerment and the Protection of the Family for Menchum, November 2013.

\section{References}

Agheneza, Z. E. 2009. "The Status of Ngie Rural Women Farmers' Socio-Economic Condition.” Journal of African and Asian Studies 44:677.

Alasah, A. A. 2008. "Women Empowerment and Community Development in Cameroon: A Case Study of NGOs and Women Organisations in the North West Province.” PhD thesis submitted to the School of Sciences, University of Southampton.

Amin, S. and S. Bajracharya. 2011. "Costs of Marriage-Marriage Transactions in the Developing World." Transitions to Adulthood 35. Retrieved (http://www. popcouncil.org/uploads/pdfs/TABriefs/35_MarriageCosts.p df).

Anderson, S. 2007. "The Economics of Dowry and Bride Price.” Journal of Economic Perspectives 21(4):151-174.

Anitha, S. 2011. "Legislating Gender Inequalities: The Nature and Pattern of Domestic Violence Experienced by South Asian Women With Insecure Immigration Status in the United Kingdom.” Violence Against Women 17(10):1260-1285.

BBC News. 2014. President Uhuru Kenyatta Signs Kenya Polygamy Law. April 29, 2014. Retrieved (http://www.bbc. com/news/world-africa-27206590).

Bishai, D. and S. Grossbard. 2008. "Far Above Rubies: Bride Price and Extramarital Sexual Relations in Uganda." Journal of Population Economics 23(3):1177-1879.

Blaine, B. E. 2007. Understanding the Psychology of Diversity. Los Angeles: Sage.

Bobga, H. 1999. Community Education and Citizenship Project. Hurcled Centre: Bamenda.

Bornstein, M. H., ed. 2002. Handbook of Parenting. Mahwah, NJ: Lawrence Erlbaum Associates Inc.

Bowling, A. 2014. Research Methods in Health: Investigating Health and Health Services. Berkshire: Open University Press.

Browning, M. 2013. Risky Marriage: HIV and Intimate Relationships in Tanzania. Maryland: Lexington Books.

Callister, L. C., C. Cobett, S. Reed, C. Tomao, and K. Thornton. 2010. "Giving Birth: The Voices of Ecuadorian Women." Journal or Perinatal Neonatal Nurses 24(2):146-154.

Calves, A.-E. 1996. "Youth and Family in Cameroon: Changing Patterns of Family Formation.” Unpublished PhD thesis. The Pennsylvania State University, University Park.

_ 2010. "Marginalisation of African Single Mothers in the Marriage Market: Evidence From Cameroon.” Population Studies 53:291-301.

Chilisa, B., I. Mohiemang, K. Mpeta, T. Malinga-Musamba, P. Ntshwarang, and G. A. Heeren. 2013. "Why Wait Til Marriage? The Determinants of Premarital Sex Among Adolescents in a Country in Sub Saharan Africa: Botswana.” Journal of Human Behavior in the Social Environment 23(8):972-979.

Colaizzi, P. 1978. "Psychological Research as the Phenomenologist Views It.” Pp. 48-71 in Existential Phenomenological Alternatives for Psychology, edited by R. Valley and M. King. New York: Oxford University Press. Come-We-Stay (CWS). 2013. Changes in Family, Marriage 
and Fertility in Western and Coastal Kenya. Retrieved (http://iussp.org/sites/default/files/event_call_for_papers/Ch anges\%20in\%20Family\%20Paper\%20iussp.pdf).

Dingome, J. N. 2013. “Isn’t Woman Woman's Worst Enemy? An Appraisal of Liking and Beyala.” In Critical Perspectives in Cameroon Writing, edited by H. N. Eyoh, A. Azeyeh, and N. Lyonga. Buea: Langaa RPCID.

Endeley, J. 2001. “Conceptualising Women's Empowerment in Societies in Cameroon. How Does Money Fit in?” Gender and Development 9(1):34-41.

Erikson, E. 1982. The Life Cycle Completed: A Review. New York: W.W.Norton \& Co.

Fonchingong, C. C. and C. A. Ngwa. 2006. "Rethinking the Cost-Benefit Equation of Women's Participation in Community-Driven Development in North Western Cameroon.” Indian Journal of Gender Studies 13(1):61-82.

Fonchingong, C., Y. E. Vubo, and M. U. Besseng. 2008. "Traditions of Women's Social Protest Movements and Collective Mobilisation: Lessons From Aghem and Kedjom Women." Civil Society and the Search for Development in Cameroon 12:35.

Fonjong, L. 2001. “Fostering Women's Participation in Development Through Non-Governmental Effort in Cameroon.” The Geographical Journal 167(3):223-234.

Frederiksen, B. F. 2000. "Popular Culture, Gender Relations and the Democratisation Everyday Life in Kenya.” Journal of Southern African Studies 26(2):209-222.

Gage, A. and D. Meekers. 1994. "Sexual Activity Before Marriage in Sub-Saharan Africa." Social Biology 41(1/2):44-60.

Gilbertson, A. 2014. "Food Security, Conjugal Conflicts and Uncertainty in 'Bangladesh' Mombassa, Kenya." In Ethnographies of Uncertainty in Africa, edited by E. Cooper and D. Pratten. Macmillan: Palgrave.

Gray, J. 1996. Men, Women and Relationships. New York: HarperCollins.

Guyer, J. I. 1984. Family and Farm in Southern Cameroon. African Research Studies. Boston African Studies Centre, Boston University.

Hague, G. and R. Thiara. 2009. Bride-Price, Poverty and Domestic Violence in Uganda, Final Report: An International Collaboration Between MIFUMI Uganda Violence Against Women Research Group, University of Bristol, UK Centre for the Study of Safety and Well-Being, University of Warwick, UK.

Hosegood, V., N. McGrath, and T. Moutltrie. 2009. "Dispensing With Marriage: Marital and Partnership Trends in Rural KwaZulu-Natal, South Africa 2000-2006.” Demographic Research 20:279-312.

Johnson-Hanks, J. 2007. "Women on the Market: Marriage, Consumption and the Internet in Urban Cameroon."
American Ethnologist 34(4):642-658.

Kaberry, P. M. 1952. Women of the Grassfields: A Study of the Economic Position of Women in Bamenda, British Cameroons. London: Colonial Office.

Kah, H. K. 2013. "Gender and Livestock Farming in Laimbweland, Cameroon 1980s-2011.” Journal of Sustainable Development in Africa 15(1):1520-5509.

Kouyate, M. 2009. Harmful Traditional Practices Against Women and Legislation. United Nations.

Lang, M. K. 2012. "The Presbyterian Church in Cameroon (PCC) and the Management of the Lake Nyos Gas Disaster.” Global South Sephis e-Magazine 8(3):6-7.

Larsen, U. 1995. "Differentials in Infertility in Cameroon and Nigeria.” Population Studies 49(2):329-346.

Lutz, W., V. Skirbekk, and M. R. Testa. 2006. "The Low Fertility Trap Hypothesis: Forces That May Lead to Further Postponement and Fewer Births in Europe." Vienna Yearbook of Population Research 4:167-192.

Manu, I. N., W. N. Andu., D. N. Tarla, and W. N. Agharih. 2014. "Causes of Cattle Theft in the North West Region of Cameroon.” Scholarly Journal of Agricultural Science 4(4):181-187.

Medcalf, N. A., T. J. Hoffman, and C. Boatwright. 2013. "Children's Dreams Viewed Through the Prism of Maslow's Hierarchy of Needs.” Early Child Development and Care 183(9):1324-1338.

Meekers, D. 1995. "Freedom of Partner Choice in Togo." Journal of Comparative Family Studies 26(2):163-178.

Meekers, D. and G. Ahmed. 2000. "Contemporary Patterns of Adolescent Sexuality in Urban Botswana.” Journal of Biosocial Science 32(4):467-485.

Moore, E. and R. Govender. 2013. "Marriage and Cohabitation in South Africa: An Enriching Explanation?” Journal of Comparative Family Studies 44(5):623-641.

Ngwafor, E. N. 1996. "Nullity: The Squaring of a Questionable Dilemma.” In The International Survey of Family Law 1994, edited by A. Bainham. London: Martinus Nijh off Publishers.

Ngwoh, V. K. 2006. "Farmer-Grazier Conflicts in Menchum Division 1943-2005. A Study of Contested Hegemony Over Land.” MA dissertation submitted to the University of Buea, Cameroon.

Njiru, R. 2008. “'Come We Stay' Marriages in Kenya: Implications for Sexual Health.” Sexuality in Africa Magazine 5(1):2-13.

Oppong, C. and R. Wery. 1994. "Women's Roles in Demographic Change in Sub-Saharan Africa.” IUSSP, Policy and Research Papers. Liege, Belgium.

Rautenbach, C. and W. du Plessis. 2012. “African Customary Marriages in South Africa and the Intricacies of a Mixed Legal System: Judicial (in) Novatio or Confusio?” McGill 
LJ 4:749-780.

Robson, C. 2011. Real World Research. 3rd ed. West Sussex: John Wiley \& Sons Ltd.

Rwenge, M. 2000. "Sexual Risk Behaviors Among Young People in Bamenda, Cameroon.” International Family Planning Perspectives 26(3). Retrieved (http://www. guttmacher.org/pubs/journals/2611800.html).

Sarantakos, S. 2005. 2005, Social Research. 3rd ed. London: Palgrave Macmillan.

Seth, M. 2001. Women and Development: The Indian Experience. New Delhi: Sage.

Sijpt, E. V. D. 2012. “'The Vagina Does not Talk’: Conception Concealed or Deliberately Disclosed in Eastern Cameroon.” Culture, Health and Sexuality 14(S1):S81-S94.

Tabutin, D. and B. Shoumaker. 2004. "The Demography of Sub-Saharan Africa From the 1950s to the 2000s: A Survey of Changes and a Statistical Assessment." Population 59(3-4):457-555.

Tem, P. M. 2013. “Administrative Handling of the Zhoa Chieftaincy Crisis: North West Region, Cameroon 1994-2008." Journal of Research in Peace, Gender and Development 3(1):9-17.

Uka, J. 2004. "The Levirate in Esu and Menchum: Does It Build or Destroy?” Paper prepared for Esu Students Association (ESA), Buea, End of Year Party.

Verhoef, H. 2005. “'A Child Has Many Mothers': Views of Child Fostering in Northwest Cameroon.” Childhood 12:369.

Vubo, E. Y. 2005. "Matriliny and Patriliny Between
Cohabitation-Equilibrium and Modernity in Cameroon Grassfields.” African Studies Monographs 23(6):145-182.

Wattenberg, B. J. 2004. Fewer: How the New Demography of Depopulation Will Shape Ourfuture. Chicago: Ivan R. Dee.

Weinger, S. 2009. “'Infertile’ Cameroonian Women: Social Marginalisation and Coping Strategies.” Qualitative Social Work 8:45.

Wong, S. 2015. "Cohabitation Reform in England and Wales: Equality or Equity.” Canadian Journal of Women and the Law 27(1):112.

Yana, S. D. 1995. A la Recherche des Modeles Culturels de la Fecondite au Cameroon: une Etude Exploratiore Aupres de Bamileke et Beti de la viille et de la campaige (In the Study of the Cultural Models of Fecundity in Cameroon: An Exploratory Study of the Bamelikes and Beti Town and City). Paris: L'Harmattan.

Zeh, P., H. K. Sandhu, A. M. Cannaby, and J. A. Sturt. 2014. “Cultural Barriers Impeding Ethnic Minority Groups From Accessing Effective Diabetes Care Services: A Systematic Review of Observational Studies.” Diversity and Equality in Health and Care 11(1):9-33.

\section{Bio}

John Mih Uka, MSc, LLM, BSc, research student, School of Social and Political Sciences, University of Lincoln, UK; research fields: domestic violence, corruption, rural social work, gender and intimacy, and witchcraft and magic. 